\title{
Primer reporte de la mancha negra en yerba mate (Ilex paraguariensis A. St.-Hill) causada por Calonectria sphatulata en Paraguay
}

\author{
First report of black spot in yerba mate (Ilex paraguariensis A. St.-Hill) Caused by \\ Calonectria sphatulata in Paraguay
}

\author{
Marco Maidana Ojeda ${ }^{1 *}$, Natalia Chamorro², Marta Barzalá1 y Edgar Fretes ${ }^{2}$ \\ ${ }^{1}$ Facultad de Ciencias Agropecuarias, Universidad Católica Nuestra Señora de la Asunción, Sub Campus Universitario \\ María Auxiliadora, Tomás Romero Pereira, Paraguay. \\ ${ }^{2}$ Consultoría independiente, Especialistas en Yerba Mate, Tomás Romero Pereira, Paraguay. \\ *Autor para corres pondencia (marcomo-1987@hotmail.com)
}

Recibido: 29/09/2015; Aceptado:21/04/2016.

10.18004/investig.agrar.2016.dic ie mbre.111-115

\section{RESUMEN}

En los últimos 5 años, las exportaciones de yerba mate (Ilex paraguariensis A. St.-Hill.) se duplicó y la demanda en el mercado interno aumentó de un 15 a $20 \%$, lo cual incentivó el incremento de la superficie de producción que favoreció la dispersión de patógenos que ocasionan problemas fitosanitarios en el cultivo. El objetivo de este trabajo fue diagnosticar la enfermedad de la mancha negra en las hojas de yerba mate causado por Calonectria sphatulata (anamorfo: Cylindrocladium spathulatum). Durante la zafra de 2014 -2015, se realizaron muestreos de hojas de yerba mate con síntomas de mancha negra en los municipios de Carlos Antonio López, San Rafael del Paraná, Mayor Otaño y Tomas Romero Pereira. En campo se realizó la descripción de síntomas y cuantificación de la defoliación en plantas afectadas. En laboratorio, a partir de muestras frescas se aislaron y purificaron cepas del hongo en medio de cultivo PDA. La identificación se hizo mediante la observación en microscopio de luz y uso de claves descriptivas. En campo, los síntomas observados inician como un punto negro y crece en forma circular hasta alcanzar los $2 \mathrm{~cm}$ de diámetro en hojas mayores a 12 meses, con defoliación grave, pero no hay muerte de plantas. En laboratorio, las características morfológicas observadas en los aislados correspondieron a Calonectria sphatulata. Es el primer reporte en Paraguay de este patógeno en plantaciones de yerba mate.

Palabras clave: Identificación morfológica,

\section{ABSTRACT}

In the last 5 years, yerba mate (Ilex paraguariensis A. St.Hill.) export doubled and its demand in the domestic market increased from 15 to $20 \%$, this has encouraged an increase on production area thus favoring the spread of pathogens that cause crop's phytosanitary problems. The aim of this study was to diagnose leaf black spot, a disease caused by Calonectria sphatulata (anamorfo: Cylindrocladium spathulatum) on the leaves of yerba mate. During the 2014-2015 harvest, in the municipalities of Carlos Antonio Lopez, San Rafael del Paraná, Mayor Otaño and Tomas Romero Pereira, a sampling of yerba mate leaves with symptoms of black spot was carried out. Symptoms description and quantification of defoliation on affected plants was done in field. In laboratory, using fresh samples, purified strains of fungus in PDA culture medium were isolated.

Identification was done by observation in a light microscope and using descriptive keys. In field, the observed symptoms start as a black point which grows in circular fashion until reaching $2 \mathrm{~cm}$ in diameter on leaves older than 12 months with severe defoliation, but without plant death. In laboratory, the morphological characteristics observed in the isolated corresponded to Calonectria sphatulata. This is the first report of this pathogen in Paraguay in yerba mate plantations.

Key words: Morphological identification, Cylindrocladium spathulatum. 


\section{INTRODUCCIÓN}

La yerba mate es una planta subtropical típica de la Cuenca de la Plata en el Hemisferio Sur Americano. Propia del sur de Paraguay y Brasil y del norte de Argentina, crece en condiciones características del bosque atlántico bajo temperaturas templadas y lluvias por encima de los $1500 \mathrm{~mm}$ año ${ }^{-1}$. Su denominación científica, Ilex paraguariensis A. St.-Hill., la sitúa dentro de la especie de arbusto mediano, verde, con propiedades medicinales y fitosanitarias (USAID 2006).

En los últimos 5 años, las exportaciones de yerba mate de Paraguay se han duplicado, con cifras de 526 t en el 2009 , $y$ de 985,3 t en el 2014 (REDIEX 2014). La demanda en el mercado interno también aumentó en un 15 a $20 \%$ en los últimos años, provocando que los precios se mantuvieran alto, e incentivó el incremento de la superficie de producción (REDIEX 2015).

El aumento del área de siembra, la domesticación del cultivo y la reducción del espaciamiento entre las plantas, está favoreciendo el desarrollo de enfermedades y la dispersión de patógenos que ocasionan problemas fitosanitarios en el cultivo (Grigoletti y Garcia 1996).

La mancha negra de la hoja de yerba mate, también conocida como pinta-preta, es la principal enfermedad fúngica del cultivo. Provoca severos daños, tanto en viveros como en el campo, provocando hasta $30 \%$ de pérdidas de las mudas (Grigoletti Júnior et al. 2000).

El agente causal, Cylindrocladium spathulatum sensu G.S. Ridley (1998) (teleomorfo: Calonectria sphatulata), fue identificado por primera vez a partir de Buxus sp., este patógeno comúnmente ha sido asociado con enfermedades en Eucalyptus sp. (Crous y Wingfield 1994).

El primer reporte de Cylindrocladium spathulatum afectando a las hojas de yerba mate fue hecho por Grigoletti et al. (1995), en viveros de yerba mate de la zona surde Brasil.

En septiembre del año 2010 se detectaron síntomas de enfermedades en las hojas y ramas tiernas de la yerba en el nordeste de Argentina en la principal región productora, lo cual ha originado estudios para identificarlos por parte del INTA de Cerro Azul y el departamento de Fitopatología de la Universidad Nacional del Nordeste (UNNE) de Misiones (Rybak et al. 2014).
Recientemente productores de plantas en viveros, localizados próximos a regiones con plantaciones de yerba mate, observaron una alta frecuencia de manchas negras en los cultivos, cuando las condiciones ambientales son de alta humedad, poca ventilación y densidades de plantas muy altas. Teniendo en cuenta la importancia del cultivo para el país y la escasa investigación en el mismo, el diagnóstico correcto y confirmación de la presencia de este patógeno en cultivos de yerba mate es crucial para posteriores estudios de manejo de la enfermedad y así evitar pérdidas a los productores ante posibles epidemias.

El objetivo de este trabajo fue identificar el organismo causal de la mancha negra asociada al cultivo yerba mate en las principales regiones productoras del Paraguay.

\section{MATERIALES Y MÉTODOS}

Durante el desarrollo de la brotación de la yerba mate en la zafra de 2014 - 2015, se realizó muestreo dirigido, tomando hojas con síntomas de la mancha negra según lo descrito por Grigoletti Júnior et al. (2000), en los municipios de Carlos Antonio López, San Rafael del Paraná, Mayor Otaño y Tomas Romero Pereira. En el momento de muestreo, se realizaron la descripción de los síntomas observados y siguiendo la escala de Ferretti (1994) se cuantificó la defoliación de las plantas afectadas.

Se extrajeron de las hojas porciones de $0,5 \mathrm{~cm}$ de tejido inmediato a los síntomas, y fueron desinfectadas con hipoclorito de sodio $(\mathrm{NaOCl})$ al $2 \%$ durante un minuto, lavada una vez con agua destilada, y posteriormente secadas para poner en placa de Petri en medio papadextrosa-agar (PDA), durante un periodo de siete días a temperatura de $28^{\circ} \mathrm{C}$ (Schaad et al. 2002).

Para la obtención de cepas puras de hongos provenientes de las muestras, se tomó una pequeña muestra del hongo de la placa de Petri y se sembró en medio agua-agar. A las 48 h se observó en el microscopio estereoscópico y con una aguja de punta fina se tomó una hifa en crecimiento y se colocó en medio PDA (French y Teddy 1980).

La identificación se realizó mediante la observación en microscopio óptico y uso de claves descriptivas (Barnett y Hunter 1986, Crous y Wingfield 1994, Crous 2002, Lombard et al. 2010).

Se realizó prueba de patogenicidad con fines reproducir los síntomas observados en el campo, a partir de las cepas 
de hongos aislados. Se seleccionó al azar un aislado del cual se generaron repiques en placas Petri con PDA como medio de cultivo, se incubaron a temperatura ambiente por 10 días. Se preparó una suspensión de esporas de $1.10^{5}$ (conidios $/ \mathrm{mL}$ ), posteriormente atomizados sobre plantines de 20 meses. Para ello se raspó la superficie de la colonia y se la puso en un tubo de ensayo al que se agregó agua destilada esterilizada, esta suspensión se filtró y se agitó enérgicamente. Se tomaron alícuotas de la suspensión de los hongos y se procedió al conteo en la cámara de Neubaüer en dos repeticiones, y se ajustó a la concentración requerida. Los plantines fueron dejados a temperatura ambiente en condiciones de alta humedad.

\section{RESULTADOS Y DISCUSIÓN}

Los síntomas observados a campo fueron la formación de manchas en forma circular en hojas de yerba mate mayor a 12 meses, en algunos casos aparecen en el centro de las hojas y en otros en el borde. Las manchas comienzan como un punto negro, crecen en forma circular y pueden llegar a alcanzar los $2 \mathrm{~cm}$ de diámetro. A medida que crecen las manchas el centro se va necrosando, hasta provocar la caída de las hojas de yerba mate en forma prematura con sentido ascendente, de abajo hacia arriba $\mathrm{y}$ de adentro hacia afuera (Figura 1 A y B).

Los focos de infección se presentaron en plantas de yerba mate asociadas con árboles, y que se encuentran con cierto sombreamiento, concordando con lo reportado por Grigoletti y Garcia (1996), desde donde se expanden en áreas más abiertas.

En el caso más severo, algunas plantas en condiciones de campo presentan defoliación grave, según la escala de Ferretti (1994), aunque se destaca la ausencia de muerte de plantas infectadas con el patógeno.
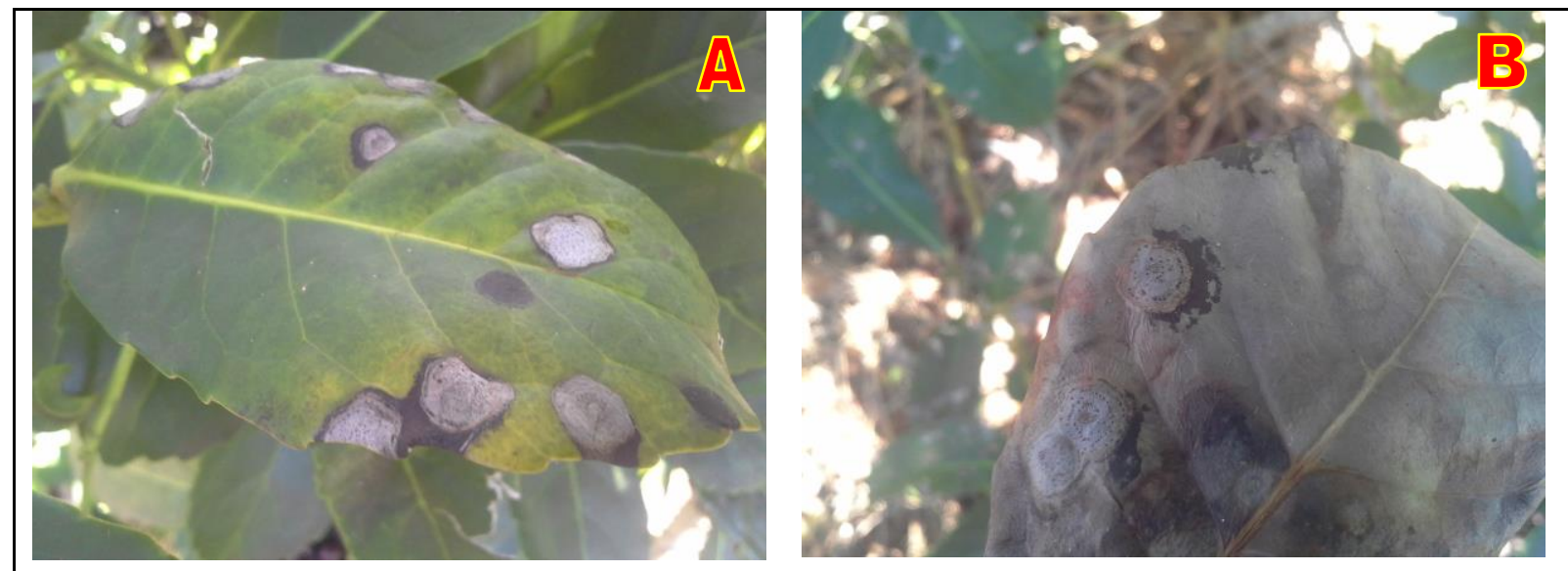

Figura 1. A: Síntomas de Calonectria sphatulata. en hojas de yerba mate con más de 12 meses de edad; B: hojas de yerba mate caídas a causa de la infección.

Los aislados en medio PDA mostraron un crecimiento micelial de color blanco durante los primeros días, tornándose de color amarillento a partir del cuarto día, y de amarillo pálido a naranja en el reverso de la placa de Petri en los días posteriores (Figura 2 A), coincidiendo con las descripciones de Barnett y Hunter (1986), y Crous y Wingfield (1994).

Se observó esporulación en medio PDA a partir de los 12 días de aislamiento (Figura 2 B). Los macroconidióforos consisten en un estípite $(25-70-4-6 \mu \mathrm{m})$ con arreglo peniciliado, septados, hialinos, lisos y con una ramificación (150-300 - 3-4 $\mu \mathrm{m})$ con terminación clavada o una vesícula simulando una espátula (Figura 2 C y D). Los microconidióforos son no septados o con una septa, hialino, alargados $(10-20-4-6 \mu \mathrm{m})$, peniciliado o subverticilado, el estípite adicional alargado (0-15 - 3-4 $\mu \mathrm{m})$ no septado o raramente septado de paredes delgadas y terminación en forma de vesícula elipsoidal o periforme. Los conidios cilíndricos, hialino, de 1-3 septos, redondeados en ambos extremos, con tamaños de 48-754-5 $\mu \mathrm{m}$ (Barnett y Hunter 1986, Crous y Wingfield 1994, Crous 2002, Lombard et al. 2010). 


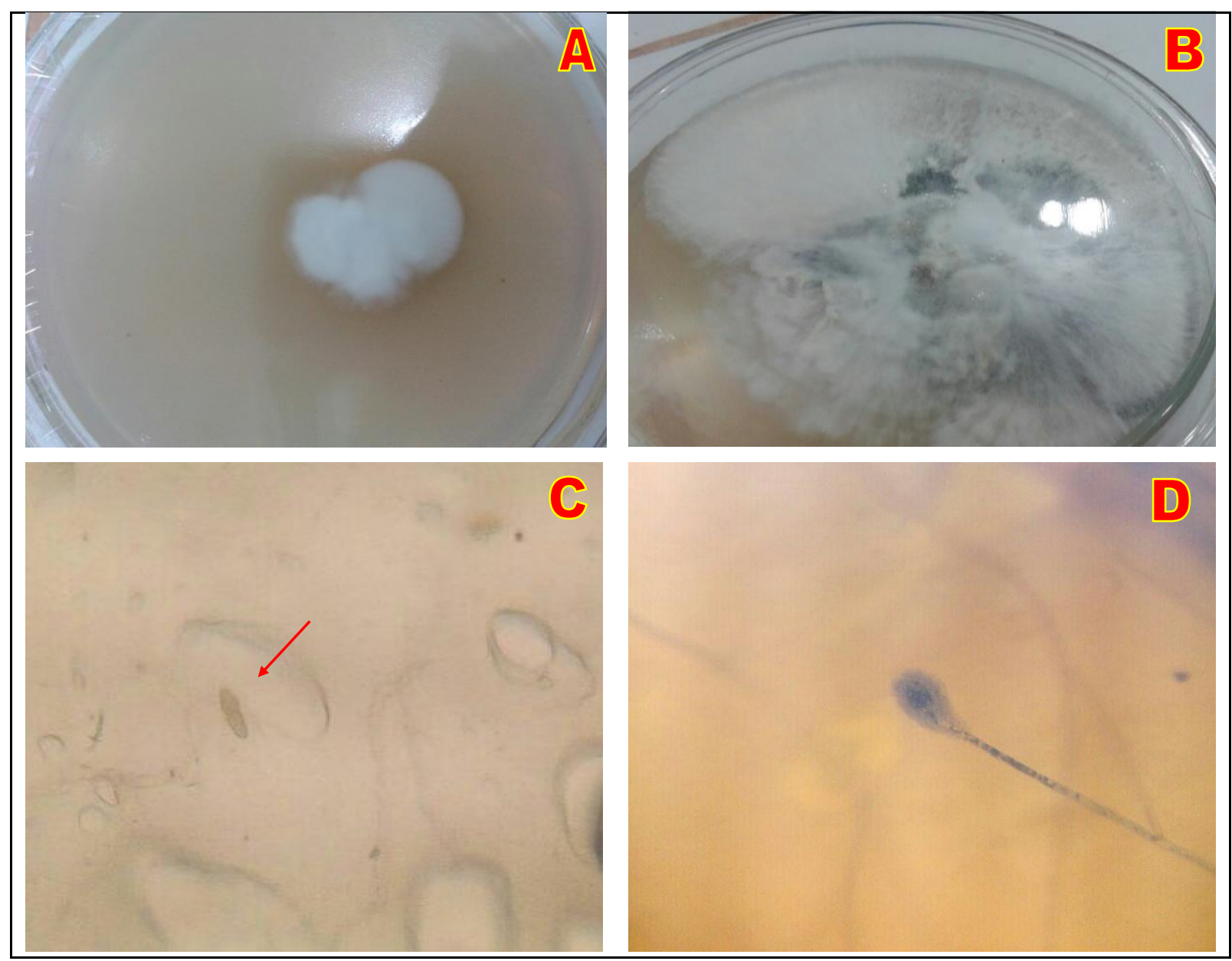

Figura 2. Calonectria sphatulata. A: colonia en medio PDA con 3 días de crecimiento; B: colonia en medio PDA con inicio de esporulación; C: conidio con una septa; D: estípite adicional de conidióforo con terminación en forma de espátula.

En la prueba de patogenicidad se observaron los primeros síntomas a partir de las 3 semanas después de la inoculación del patógeno, siendo estos similares a los observados a campo.

En Paraguay es la primera vez que se está reportando esta enfermedad en plantaciones de yerba mate en producción y por lo tanto no se sabe si es esporádica o definitivamente se ha instalado en el cultivo como una nueva enfermedad.

\section{CONCLUSIONES}

Con base en las características morfológicas y las pruebas de patogenicidad se confirma que el organismo causal de la mancha negra es Calonectria sphatulata. Este es el primer reporte de este patógeno asociado al cultivo de yerba mate en condiciones de campo en el Paraguay.

\section{REFERENCIAS BIBLIOGRAFICAS}

Barnett, HL; Hunter, BB.1986. Illustrated genera of imperfect fungi. 4 ed. New York, Estados Unidos de América, Macmillan Publishing. 217 p.

Crous, PW; Wingfield, MJ. 1994. A monograph of Cylindrocladium, including anamorphs of Calonectria. Mycotaxon 51:341-345.

Crous, PW. 2002. Taxonomy and pathology of Cylindrocladium (Calonectria) and allied genera. Minnesota, Estados Unidos de América, APS. 278 p.

Ferretti, M. 1994. Especies forestales mediterráneas: guía para la evaluación de las copas. Bruselas, Ginebra, CEE-UN/ECE. 93 p. 
French, ER; Teddy, TH. 1980. Métodos de investigación fitopatológica. San José, Costa Rica, IICA/CATIE. $289 \mathrm{p}$.

Grifoletti Júnior, A; García Auer, C; Tadeu, E. 2000. Manual de identificação de pragas e doenças da ervamate (Ilex paraguariensis St. Hil.). Colombo, Brasil, Embrapa. 24 p.

Grigoletti Junior, A; Auer, CG; Alfenas, AC; Crous, PW. 1995. Leaf spot, shedding and death of seedlings of erva-mate (Ilex paraguariensis) caused by Cylindrocladium spathulatum. Abstracts of the annual meeting of the Brazilian Society for Plant Pathology, Sao Paulo, Brazil.

Grigoletti Júnior, A; Garcia Auer, C. 1996. Doenças da erva-mate: identificação e controle. EMBRAPACNPF. Circular Técnica, 25. 18 p.

Lombard, L; Crous, PW; Wingfield; BD; Wingfield, MJ. 2010. Systematics of Calonectria: a genus of root, shoot and foliar pathogens. Studies in Mycology 66: $1-14$.

REDIEX (Red de Inversiones y Exportaciones, Paraguay). 2014. Exportaciones paraguayas Yerba Mate (volumen en toneladas; datos VUE). Asunción, Paraguay. (no publicado).
REDIEX (Red de Inversiones y Exportaciones, Paraguay). 2015. Yerbateros buscan aumentar el cultivo para más producción (en línea). Consultado 02 jun 2015. Disponible en http://www.rediex.gov.py/yerbateros -buscanaumentar-el-cultivo-para-mas-produccion-not 431

Rybak, M; Rybak, R; Cabrera, MG; Alvarez, RE. 2014. Enfermedades de Yerba Mate y Té en Misiones y Norte de Corrientes. 2 ed. Cerro Azul: INTA EEA CERRO AZUL (Miscelánea No 66), 32 p.

Ridley, G. 1998. New plant fungus found in Auckland box hedges (Buxus). Forest Health News No. 77.

Schaad, NW; Jones, JB; Chun, W. 2002. Laboratory Guide for identification of plant pathogenic bacteria. 3 ed. Saint Paul, Estados Unidos de América. American Phytopathological Society (APS) Press. 373 p.

USAID (United States Agency International Development, Estados Unidos de América). 2006. Welcome Yerba Mate. La novedad en el mundo de las infusiones. REDIEX/PARAGUAY VENDE. Asunción, Py. 43 p. 